\title{
Pseudoscience and Idiosyncratic Theories of Rational Belief
}

Nicholas Shackel. 28.2.2013

To appear in The Philosophy of Pseudoscience. Eds. Pigliucci, M. and Boudry, M. Chicago: Chicago University Press.

\section{Introduction}

I take pseudoscience to be a pretence at science. I will not rehash the difficulties in demarcating science. Pretences are innumerable, limited only by our imagination and credulity. As Stove points out, 'numerology is actually quite as different from astrology as astrology is from astronomy' (Stove 1991, 187). We are sure that 'something has gone appallingly wrong' (Stove 1991, 180) and yet 'thoughts...can go wrong in a multiplicity of ways, none of which anyone yet understands' (Stove 1991, 190). ${ }^{1}$ Often all we can do is give a careful description of a way of pretending, a motivation for pretence, a source of pretension. In this chapter I attempt the latter. We will be concerned with the relation of conviction to rational belief. I shall be suggesting that the question of whether an enquiry is a pretence at science can be, in part, a question over the role of conviction in rational belief, and that the answer is to be found in the philosophical problem of the role of values in rational belief.

\section{The borders of science and pseudoscience}

Pseudoscientists seek to be taken seriously for the same reason that scientists claim our attention, that the propositions of a rigourous and rational science are more worthy of belief than the common run of opinion. But why do they wish to be taken seriously in this way? Certainly in some cases, cases of outright fakery and deceit, there is some interest of theirs that they think will be served by exploiting our credulity. These people don't think that they are scientists, they just want you to think they have the imprimatur of science. Others are just engaging fools who fool themselves and others. Yet others may have a very strong and deep need to bolster certain beliefs and must find whatever tools they can to do it. These errors are important but have been widely analysed and do not manifest the problems of philosophical interest in this chapter. My concern here is not with the worst of pseudoscience but with the best. Equally, my concern is not with the best of science but with, if not the worst, with ways in which it can go and has gone bad.

Acquaintance with the history of science inclines me to think that science has grown out of practices that were confusions of what we would now call science and pseudoscience, ${ }^{2}$ distinctions which we can make with hindsight but which were not clear to the practitioners of the time. For them, the issues were obscure and so were the surrounding methodological and philosophical questions. Of course, the non-scientific parts were not at that time exactly pretences, since no one knew better, nor were they motivated by wanting the prestige and authority which science now has. Rather, what we had were sincere enquirers wandering around in the borders of science and pseudoscience, sometimes getting lost and sometimes finding something.

The borders are still inhabited. The pseudoscientists who are of greatest philosophical interest are reasonable and sincere pretenders at science: trained enquirers who appear to want to know and who, if they pretended well enough, might even cease to

\footnotetext{
${ }^{1}$ Stove's target is not pseudoscience alone but includes philosophical horrors and the problem of our lack of what he calls a nosology (a classification of diseases) of thought.

${ }^{2}$ See, for example, Dobbs 1975
} 
be pretenders and become the real thing. Also of interest are those who are the real thing but who are becoming pretenders. Something about the borderers makes us wonder whether they really do want to know. We see the appearance of enquiry but we detect the portents of ideological conviction in the propositions pursued and in the manner of pursuit. The enquiry and the form it takes may arrive wreathed in the philosophical glories of a rooted conviction. We must wonder whether conviction is driving the enquiry where it wills.

Yet trained enquirers are often thus driven by strongly held conviction. In concurring with Stove above and in contributing to this book I am expressing my convictions. It will perhaps be no surprise to the reader if my destination here is consonant with my convictions. Is being a pseudoscientist borderer just having the wrong convictions then? Well maybe, but something more is required than a dogmatic yes. Maybe all convictions are wrong! If not, then we need to know the basis for distinguishing right and wrong convictions.

Science is hard and we are still learning how to do it. Sometimes we find our way but which route the discipline of empirical method indicates depends on philosophical assumptions. Hence the room for the borderer's philosophical defence of an enquiry. Among those assumptions are what amount to theories of rational belief and to take a route is to accept, if only tacitly, such a theory. These theories are the philosophical assumptions that bear on whether conviction is an illicit input to science. Hence I think that knowing the proper relation of conviction and rational belief will help in distinguishing science and pseudoscience at the borders.

\section{Conviction}

In general, our convictions are assemblies of deeply intertwined factual and evaluative beliefs that are important to us and hang together for us. Despite being beliefs, their importance to us makes it unclear to what extent conviction is disciplined by truth. Things would be simpler if we could reject conviction outright. Yet conviction is not simply a bad thing. It is often necessary in order for us to persist in a hard task despite difficulties and setbacks. When shared it creates affiliations and alliances of the most reliable kind and thereby furnishes not only the practical benefits that flow from trust safely placed but a good more highly prized still, the feeling of being with like minds, of being at home and at one with others.

It is, then, perhaps not suprising that conviction is common in us, indeed, that it is often something of which we are proud. Yet with the good comes the bad. We parade our convictions and demand submission to them. We indoctrinate our children in our convictions and think it right to do so. We cast creeds before strangers and know the unbeliever by his pause. Conviction can be ideological and fanatical. There is often something that we want to be true, that we are sure it matters a great deal that it be true and that we are so sure is true that denial is heresy and deniers heretics to be anathematized and cast out.

There are important empirical questions in the middle of this, puzzles over the muddle of belief, desire and self-delusion that we inhabit. Granted, for example, the apparent role of belief as information carrier, and the practical value of information, how could we ever end up with a psychology that subverts that role and turns it to other purposes? Economists and psychologists have brought to our attention the general importance of self deceit, signalling, persuasion and commitment strategies in which belief entrained to something other than truth can have a role (Spence 1973; Hechter 1987; Bulbulia 2007; Caplan 2007; Rasmusen 2007; Trivers 2011). Presumably there is 
some trade-off between informational loss and practical gain on which, if selection pressure can bear it will have borne.

Whilst I look forward to having good empirical answer to those questions, and I think such answers will be a valuable contribution to our understanding of pseudoscience, they are not my concern here. I am concerned with the rights and wrongs of conviction because I think this will tell us something about science and pseudoscience, will articulate and distinguish something they share and something that goes wrong in the case of pseudoscience. That is to say, I am not concerned with the causal explanation of how we come to conviction but with the evaluation of its role and our views of such evaluation.

So for our purposes it is the normative link between conviction and belief that is crucial. People who have convictions are by and large convinced also that their conviction is what ought to be believed. This is what can lead pseudoscientists to think that if science says otherwise it must be in error and since science is our organized project of enquiry we need to reformulate it to give the right answers. This can strike us as back to front, but is it? Scientists have sometimes had convictions at odds with science and have rightly reformulated science as a result. To determine whether this is just luck in being right we need to know what ought to be believed and what relation what ought to be believed has to science.

\section{Ethics of Belief}

Well, what ought we to believe? Presumably, whatever the determinants of right belief determine to be right to believe. But what are those determinants, how widely do they range, how do they determine the rightness of belief and relative to what do they determine the rightness of belief? These questions are the central questions of the ethics of belief. ${ }^{3}$

A normative principle that many find intuitive is that what you ought is whatever is rational. So a theory of rational belief is commonly taken to be the formal answer to what you ought to believe. Substantive disputes can then be conducted in terms of disputes over substantive theories of rational belief.

A traditional answer in this line has been to say that you ought to believe in accord with reasons, rather than, for example, with emotion or faith. When put like that, however, it has drawn the response that 'the heart has its reasons of which reason knows nothing' (Pascal 1670, XVIII) and that faith has its reasons too. In recent literature (e.g. Meiland 1980; Heil 1983; Haack 1997; Stanley 2005) this conflict manifests in the controversy over whether practical considerations play a role in what we ought to believe-practical considerations such as the loyalty owed a friend or the better outcome that having a certain belief may secure- or whether only theoretical considerations count.

The distinction between practical and theoretical considerations can be cashed out in a number of ways. Sufficient for our purposes is to note that theoretical considerations are, in broad, purely truth directed or truth conducive considerations; I say in broad in order to include internalist notions such as consciously accessible principles of inference

\footnotetext{
${ }^{3}$ It is an error is to mistake the ethics of belief for epistemology. The thought that the output of theories in epistemology settle the ethics of belief is sometimes assumed dogmatically. To do so is to miss vital questions over the normative status of such theories and the nature of the normativity referred to when such theories are expressed in normative terms. For example, a causal theory of knowledge may be a purely positive theory. If such a theory identifies the justification of the belief with being caused by the fact believed there is a question over whether this is really a normative use of the term 'justification'. If it is there is a further problem in explaining how being caused by a fact makes something normative and in what way is it normative.
} 
and evidence as well as externalist notions such as reliably based beliefs. ${ }^{4}$ To cut a long story short, we are going to use 'evidence' to cover the purely theoretical considerations and 'values' to cover the practical considerations. I use the latter because they are essentially ethical considerations, in the broad sense of the term concerned with those things constitutive of a worthwhile life ${ }^{5}$. We are going to call believing as and insofar as the purely theoretical considerations determine to be correct believing in accordance with the evidence.

\section{Evidentialism and Pragmatism.}

Strict evidentialists (such as Conee and Feldman 2004) hold the stringent position that you ought and ought only to believe in accordance with the evidence. At the other extreme, pure pragmatists hold that only values count. Pure consequentialism can end up here, for example, we could understand Sidgwick 1906/1981 Book 3 Ch 14 as taking this position. ${ }^{6}$ Between these extremes we can distinguish positions that are relatively more or less evidentialist, more or less pragmatist. Because this can be done in two ways, distinguishing the kinds of values and distinguishing the ways values interact with evidence to determine right belief, there is a complex range of positions available for specific substantive theories in the ethics of belief.

In terms of the kinds of values, an evidentialism with a minimal concession to pragmatism would be an axiology that confines the relevant values to the value of knowledge or virtuous belief, or to some notion of epistemic utility that is not evidential yet still purely epistemic. ${ }^{7}$ A purely hedonistic axiology, on the other hand, would take us to an extreme pragmatism.

In terms of the ways values and evidence interact, a minimal concession to pragmatism would be for values and evidence to have entirely independent roles in determining what ought to be believed: values determine which propositions are worth believing or disbelieving and that is the entirety of their role; whether we ought to believe or not is then fixed by the evidence. We could call this pure factorism. This is an appealing position and is a natural retreat for the strict evidentialist. From pure factorism we can move to impure factorism, where whilst the roles of evidence and values remain distinct, they are not wholly independent. For example, perhaps the values can break evidential ties or determine starting places when evidence can't. Positions in which values and evidence are both taken to have the same role qua reasons in determining what ought to be believed leave factorism behind, and varieties of such positions will fall out of different accounts of how reasons 'add up', whether they are commensurable, comparable, incomparable, whether they can silence or exclude one another, and so on. ${ }^{8}$

\footnotetext{
${ }^{4}$ This water is muddied somewhat in some discussions of deontological notions of internalist justification for belief (Alston 1988), but even then, rarely do contra-truth practical considerations feature as justifiers. Rather, the worry is whether the combination of the ought-implies-can principle and belief being outwith voluntary control undermine responsibility, and thereby the possibility of justification, for belief. We shall return below to the status of deontology in the justification of belief.

${ }^{5}$ See Williams 1985, Ch. 1 for this notion of the ethical and why it is broader than morality.

${ }^{6}$ Moore, at least, interprets him in this way, see Moore 1903, 85.

${ }^{7}$ Whether there is any such thing is unclear. Exploration of consequentialist epistemology intended to be analogous to consequentialism as virtue epistemology is to virtue (such as Percival 2002) have tended to leave the nature of epistemic utility un-defined whenever they have gone beyond taking truth as the good.

${ }^{8}$ These metanormative issues have been discussed more deeply in ethics than in epistemology, e.g. Raz 1975/1999; Dancy 2000; Broome 2006; Schroeder 2007
} 


\section{Science and the ethics of belief}

It is tempting to think that addressing pseudoscience does not require us to take a detour through the ethics of belief. Are not pseudoscientists as committed as scientists to taking the aim to be truth? So the truth is what ought to be believed and the issue is simply how pseudoscientists pursue this is a distorted way! It is certainly true that the literature on pseudoscience has presupposed something like this and for that reason authors in this area have also a tacit and unanalysed presupposition of strict evidentialism. ${ }^{9}$ I think it would be fair to say that strict evidentialism has also been a presupposition of the public face of science.

Philosophical analysis can seem to be a matter of raising questions that do not need asking. This is especially the case when, as is common in philosophy, at the end of the analysis no definitive answer is offered. To some extent that will be the case here. However, it seems to me that there is a kind of idiosyncrasy in pseudoscience that can only be made sense of by investigating why we have these presuppositions and whether they are well or ill-founded. So I am aiming to show an aspect of pseudoscience that has been neglected. That it is neglect rather than correct peremptory dismissal depends partly on showing the presuppositions to be less well-founded than is presumed and partly on the extent to which such a dismissal poses problems also for understanding science. I am now going to sketch briefly some weaknesses of the presuppositions before we turn to what is for us a central issue: whether pragmatism is avoidable. My answer will be that it isn't and we will then turn to considering the consequences.

The nature of science is itself in dispute. For a start, instrumentalists philosophers of science such as Van Frassen (1976) would not agree that science aims at the truth. Whether science has a single aim and whether that aim is truth is also questioned by scientists, some of whom explicitly reject talk of truth in science and regard truth as an unscientific concept best left for philosophers to waffle irrelevantly about. Instead they abjure the term and wish only to discuss models and their uses. Turning to pseudoscientists, they too may state their aim for science in other terms and sometimes explicitly in terms of conviction, for example:

the Discovery Institute ... talks about a strategy to "defeat scientific materialism" and "reverse the stifling dominance of the materialist worldview, and to replace it with a science consonant with Christian and theistic convictions.” IDEA 2011 (my emphasis).

Taking truth as the aim of science faces obvious problems. Truth cannot be an aim like a target because when we see the truth we have already attained our aim. If someone was just lucky at guessing the truth then on that basis they'd count as a scientist but obviously that is not right. So achieving the truth is not sufficient for science. Nor is it necessary. Scientists are not simply given the truth and what is meant by 'scientific truth' need not even be true! Rather, what may make a doctrine scientific is that it is the output of a rational enquiry, thereby being what is rational to believe, which is to say, what ought to be believed.

Even if we accept that truth is the aim of science, the nature of truth is up for dispute. The assumption that this aim takes us swiftly to strict evidentialism depends on assuming a correspondence theory of truth ${ }^{10}$. But if semantic anti-realism is true, truth is

\footnotetext{
${ }^{9}$ These were my presuppositions too.

${ }^{10}$ In which truth is correspondence to the facts. The most recent versions are given in terms of truth makers rather than facts.
} 
something like warranted believability. ${ }^{11}$ In that case the aim of science just is whatever ought to be believed. The fact that truth has been thus defined in normative terms means that values can now count as truth conducive considerations, but that is a merely verbal victory for evidentialism. Evidentialists want to exclude values from counting towards what ought to be believed and if values count in this way the pragmatists win. So truth being the aim doesn't imply that we can ignore the ethics of belief.

Furthermore, some scientists, perhaps especially in the social sciences (e.g. Sampson 1978; Rabinow and Sullivan 1979), reject the notion of facts that are independent of values. In such a case even correspondence truth would be relative to values, and so not even a correspondence theory of truth guarantees that we can ignore the ethics of belief.

Finally, science is respected for having a wider social and moral significance in being a source of what is worthy, or more worthy, of belief. It is exactly this respect that pseudoscientists wish to have. But that wider social and moral significance is a matter of taking science to be a source of what ought to be believed. So the dispute over pseudoscience depends in part on the ethics of belief.

\section{Some degree of pragmatism unavoidable}

I am now going to argue that strict evidentialism is false, which implies that any true theory of rational belief must have a pragmatic element. The essential problem is that arguments for strict evidentialism fail by failing to attend to an important distinction in kinds of normativity and to a correlate distinction in what we are talking about when we are talking about rationality.

It is regrettable that our terminology is so congested here. To get clear we must distinguish two uses of the word 'rationality'. The first is the sense we used above, in which we took a theory of rationality to answer the question of what ought to be believed. ${ }^{12}$ The second is the sense that characterises our mentality and agency. When I need to be careful in distinguishing these senses I shall speak of normative rationality for the first sense and intrinsic rationality for the second.

A central kind of argument for strict evidentialism is to formulate a theory of normative rational belief in terms of the intrinsic rationality of belief (for example, Adler 1999, 2002) that is, the correctness of a mental state whose role in the mental economy is to represent the world as in fact being a certain way. This apparently offers a short path to evidentialism For example, one can argue that if belief were to be otherwise guided, then the rational economy would have to have some other state that was purely truth directed in order to keep track of how things are, thereby to determine whether believing how things are is practically better or not. But in that case belief would be otiose, since its intrinsic role in the rational economy is played by that other state.

Thus a putative short path to evidentialism, but a path taken at the cost of evading the question. Yes, in one sense of 'ought', ${ }^{13}$ the sense that here expresses what is correctly responsive to the role of belief in a system of mental states constituting rational agency, you ought to believe in accordance with the evidence. But then, what the ethics of belief is asking is whether what is intrinsically rationally correct to believe is what ought to be believed, in precisely the sense of 'ought' that goes beyond mere intrinsic rational

\footnotetext{
${ }^{11}$ Strictly speaking I've moved a bit swiftly here, since usually it is defined in terms of warranted assertibility and then we have to work on the route to belief. That would be an un-illuminating technical journey for our purposes.

12 This is the same sense as when we take it to answer the question of what we ought to do.

${ }^{13}$ A sense which I have called the correctness sense of 'ought', see Shackel 2004 Ch. 2.
} 
correctness and advances on what is right. ${ }^{14}$ After all, it may be that the greedy nephew who wants his aunt's fortune ought to poison her in the first sense ${ }^{15}$, but not in the second. So the whole question over strict evidentialism is whether what is intrinsically rational is what is normatively rational. Absent some further argument, this kind of approach to strict evidentialism merely assumes what it was supposed to prove.

An assumption of the argument just considered is that belief is truth directed, that truth is the aim of belief. Prima facie there is something right in this thought (although there are outright rejections in the literature, e.g. Rosenberg 2002; Steglich-Petersen 2006; Gluer and Wikforss 2009). Finding and delimiting what is right has proved to be harder than it might at first appear (Velleman 2000; Wedgwood 2002; Steglich-Petersen 2006; Engel Forthcoming). A natural approach is to think that being true is necessary and sufficient for being what you ought to believe. Necessity is appealing but fails if, for example, you can have strong enough evidence for a falsehood that you ought to believe it. Sufficiency fails more clearly since presumably it is permissible not to believe the myriad trivial truths even if you had the capacity to do so. The latter difficulty is usually addressed by a clause requiring significance (which can include significance for further enquiry, but then in the end must be grounded in the significance of that enquiry). What is significance if not a practical consideration? Certainly, significance may sometimes be the value of knowledge or the value of excellence in belief, but in appealing to these we have gone beyond purely theoretical grounds into the ethical value of theoretical goods:

Knowledge is valuable because knowledge of certain matters adds so importantly to the flourishing of one's life individually, and of life in community. (Sosa 2010, 189)

Another path to evidentialism is to take standard answers in epistemology to the question of justified belief to be answers to our question. But consider the telling qualification at the end of this remark: 'another kind of normative fact-epistemic facts....concern what we ought to believe, provided that our beliefs are aimed at the truth' (Schafer-Landau 2006, 226). The provision is accurate and significant, and leaves clear room for the broader question. Furthermore, just because the deontological vocabulary deployed in epistemology is the same as that deployed in ethics it doesn't mean that the normativity in play answers to the ethics of belief. Alston, for example, uses some of the difficulties that arise if we assume it does to argue that 'deontological justification is not epistemic justification' (Alston 1988, 293). That is to say, despite the normativity of epistemic justification sounding like a notion correlative to the normative concerns of the ethics of belief, it isn't. My suggestion for understanding this disjunction is that the normativity of the epistemic facts discussed in epistemology is correctness rather than directivity; the issue over whether what is correct is also right is not much considered and is often assumed without argument.

Whatever the obscurity in the use of deontological notions within epistemology, whether they are to be taken as merely a loose analogy to their use in ethics or whether they are to be taken full bloodedly, when we come to the ethics of belief we have come precisely to the place where analogy is laid aside and identity assumed. The ethics of belief is where we ask what ought to be believed, in precisely the same sense as in ethics we ask what ought to be done. In so doing we move to the widest or deepest or most fundamental normative perspective, the perspective not of correctness but of directivity, marked by the directive sense of 'ought', and are looking for the final and complete

\footnotetext{
${ }^{14}$ A sense which I have called the directive sense of 'ought', see Shackel 2004 Ch. 2.

${ }^{15}$ The correctness of instrumental rationality. Cf. Kant's hypothetical imperative.
} 
answer that takes everything into account. This is sometimes expressed as the question of what, all things considered, we ought to do or believe. ${ }^{16}$

On occasion it has been argued that the answer to any such question is determined once we know what is morally right (e.g. Prichard 1912) but that is clearly a further question. So identifying the senses of 'ought' in the questions of what ought to be done or believed, absent a prior commitment to morality over-riding, is not to identify right belief with moral belief. It is merely getting clear which question is being addressed in the ethics of belief. When we have determined what is prudent, we have still more work to do before we have answered what ought to be done, likewise, when we have determined what is correctly in accordance with the evidence, we have still more work to do before we have answered what ought to be believed. We have to determine whether what is intrinsically rational is also what is right.

The clarity of thus distinguishing what is intrinsically rationally correct from what is right can be obscured when we define reasons in terms of what ought to be believed, thereby returning to the normative sense of 'rational'. Once again we can be tempted to evade the difficulty. If, having defined reasons as the determinants (whatever they are) of what ought to be believed, we now identify them with the determinants of the intrinsic rationality of belief (evidence), we have taken a question-begging shortcut to evidentialism from the other direction. Pragmatists can similarly evade the difficulty by staunchly affirming reasons of the heart and faith. Instead, given this definition, having identified what is right to believe with what is normatively rational to believe, now the disagreement between evidentialists and pragmatists has to return to where we started. Deciding to call the determinants of what we ought to believe 'reasons' hasn't advanced us one bit, since we must still consider whether such reasons include theoretical considerations alone or include practical ones as well.

We can now see that the move from the normative to the intrinsic sense of rational belief is also a move between two correlative senses of 'ought', the 'directive' sense that attributes the normativity of what is right and the 'correctness' sense that attributes the normativity of correctness alone. Insufficient marking of this division within normativity can lead us to assume that which was to be proved. We can do this because taking the argument through a truism that to be rational is to act and believe in accordance with reasons leads us to miss the shift in senses of 'rationality'. When we start at the intrinsic rationality of belief and identify the intrinsic reasons derived on that basis with normative reasons we have begged the question against pragmatism. And if we start at normative reasons and derive the rationality of belief, we only get back to intrinsic rationality of belief if we started by assuming that normative reasons are evidence.

The argument I have just given is not conclusive but I think it makes clear that the burden is on the strict evidentialist to advance beyond the mere assumption of the identity of normative rationality and intrinsic rationality. Absent some good argument to that effect I think we have to give up on strict evidentialism. I do not know of such arguments: I think some degree of pragmatism is unavoidable.

\section{Source of pretension}

So now we can draw the threads together to characterise the source of pretension that it has been my purpose to describe. We are concerned with the role of conviction in rational belief in aid of understanding the borders between science and pseudoscience. Recall that we are not concerned with the pseudoscience of fakes, fools and fanatics and hence are

\footnotetext{
${ }^{16}$ And in the latter case especially it is sometimes held that it is without answer because the question is without meaning, see Feldman 2000, 694.
} 
not interested in blind conviction. Pseudoscientists of the most problematic philosophical kind are those who are sincere, reasonable, scientifically trained, driven by conviction in a way similar to scientists and who seek to defend their pretence at science as rational enquiry.

Essentially, the source of pretension is that, despite the lip service paid to strict evidentialism, there is a tacit subscription by enquirers to pragmatism, a subscription driven by conviction and leading to the deployment of conviction in enquiry. The tacit pragmatism allows there is a proper role for conviction, the public evidentialism rules it out and discomfort at this conflict forestalls explicit philosophical enquiry into the proper and improper roles for conviction. Because conviction results from and is expressive of our values we do not renounce it. Partly because its role is under analysed it has freest rein wherever there is obscurity in enquiry. The upshot is that conviction has a significant role in enquiry and also (as has been long recognised) a potentially corrupting role in enquiry. The question is what to do about it.

If strict evidentialism is true, the answer is straightforward. Under strict evidentialism any intrusion of values and convictions into science looks only peculiar and irrational. Rather, scientists must be purely disinterested and dispassionate enquirers. A problem here is that many scientists are neither disinterested nor dispassionate enquirers. So if strict evidentialism is true we can make no distinction between scientists who are driven by their convictions and pseudoscientists who are driven by their convictions: neither are doing science. Still, that might be right and we might just need to train the conviction out. There are however reasons to be uncomfortable with that conclusion, reasons independent of the argument above against strict evidentialism.

The irrationality of conviction has been a doctrine of the philosophy of science since Bacon ${ }^{17}$ and remained largely unquestioned until Polanyi (1966) pointed out the importance of tacit knowledge and Kuhn (1970) convinced us that philosophy of science must attend carefully and more respectfully to what scientists actually do. These made the doctrine look false even when we sustain the distinction between the context of discovery and the context of justification. Yes, sometimes it is irrational but sometimes it isn't, so what makes the difference? How does a theory of rational belief countenance conviction?

Pragmatic theories of rational belief, theories that countenance some role for values, can allow the intrusion of values and conviction without necessarily marking them irrational. Such theories, in distinguishing proper and improper roles for values, distinguish proper and improper roles for convictions, and may thereby distinguish the convictions of scientists from those of pseudoscientists. The kinds of theories of rational belief surveyed above are very different in their import for the proper influence of values and this is in part why what one person sees as illicit influence another may see as required. What would be needed in any particular case is an analysis of just what roles convictions are playing in a particular enquiry, what that entails for the role of values in that enquiry and what kind of theory of rational belief countenances such a role for values. Absent knowledge of the true theory of rational belief, an issue which is not likely to be settled any time soon, any such analysis brings with it the possibility of extensive and deepening philosophical dispute.

A new area of work for the analysis of pseudoscience

A full analysis of this source of pretension depends on knowing which principles are the true principles of rationality. Certainly we have some knowledge here, but less than we

\footnotetext{
${ }^{17}$ See his four idols (Bacon 1620/1994, Book 1 Aphorisms 38-44) especially of the cave and of the theatre.
} 
would like, and far less in the specific area that has been our focus. The literature on the ethics of belief has explored the role of values but their import for the epistemology and practice of science is barely discussed. Strict evidentialism has been the assumption in the literature on pseudoscience and because it has been the assumption the source of pretension that I have sought to bring into focus here has been neglected through being dismissed as merely irrational. Since strict evidentialism is probably false, to advance the analysis we need new work on the import of pragmatic theories for understanding the rational role of conviction in science. Getting this right will, I think, help us determine new markers of science and pseudoscience.

Once we see that we cannot defend strict evidentialism we must concede that we may have been begging some questions against sophisticated pseudoscientists. Furthermore, by failing to take on directly those elements of their defences that are grounded in explicit or implicit theories of the role of values in rational belief our prophylaxis has been less effective. In evading the issue of the role of values, the convictions of truth wanters such as myself may have struck pseudoscientists as mere prejudice and they may have resented our attitude as bigoted.

A further point that becomes evident is that pseudoscience is closer to us than the easy examples we like to reject. We can see powerful convictions and accompanying bigotries lurking in almost any area of science with strong practical import, and we see it on both sides of controversies. There is no shortage of ideologically driven true believers in economics, social science, psychology and climate science. Perhaps in part because these disciplines study complex systems, which are by their nature obscure, conviction has an especially free rein here.

The range of strategies available for the philosophical defence of pseudoscience is wider than has been previously considered. The fact that pragmatic theories of rational belief are defensible means they can be deployed in defending a programme of enquiry and controversy over that enquiry can be addressed by moving to the controversy over those theories. The fact that pragmatic theories of rational belief have some tacit currency in our general intellectual lives and have some intuitive appeal when explored is in part an explanation of the extent to which both scientists and pseudoscientists engage in pragmatically tinged philosophical defences of their projects. It will seem right to be motivated by conviction in defending their projects and when their convictions drive them to thinking that science is in need of reform they will have to articulate that reformed science on the basis of some theory of rational belief, a theory that licences the role their convictions are playing. Hence do inhabitants of the borders rationalise their activities in the borders. The question is whether they are doing it in the psychiatric or the success sense. Developing a better understanding of the rational role of conviction will help us here.

As Quine pointed out ${ }^{18}$, sophisticated systems of belief have immense capacity for resisting unwanted change in one area by making changes elsewhere. A theory of rational belief itself is one such area. Put these elements together and we have the materials for the self-enclosed systems of enquiry and belief that we can fall into. Because the same materials are deployed in our open enquiries and the differences are subtle and philosophically disputable we can hardly be surprised that the borders of science and pseudoscience are inhabited. For these reasons distinguishing science and pseudoscience can in part be a matter of distinguishing the nature of an implicit theory of rational belief.

\footnotetext{
${ }^{18}$ e.g. "Any statement can be held true come what may, if we make drastic enough adjustments elsewhere in the system.”Quine 1951 §6
} 
Insofar as we don't know the true principles of rationality we are unable straightforwardly to distinguish true and false theories of rational belief. What I think we can often distinguish are philosophically defensible theories from idiosyncratic theories. Even if we cannot fully specify the principles being transgressed, there comes a point at which we recognise a theory as being bent ingeniously and entirely to preserving the precious propositions.

The literature on pseudoscience has focused on idiosyncrasy in the treatment of the evidential aspects of rational belief. We have not spent much time analysing idiosyncrasies in the treatment of values. The fact that values have some role means that the ways theories of rational belief can go wrong are more varied than the literature has tended to address. If we cannot simply dismiss the influence of values as distortion, then we have to tease out the range of potentially legitimate influences and point out idiosyncrasies where they can be identified. Further complications arise when we consider the interaction of values and evidence as warranted by some theories. Indeed, I think work on such interactions will illuminate some puzzles about pseudoscience. One problem here is that the distortions are sometimes so bizarre and obviously wrong that it is very hard to understand why anyone should ever end up with them on a purely evidential basis. If values have a proper input to rational enquiry it is easier to understand how mistakes could be made and lead to improper inputs. For example, it is hard for us now to understand the widespread acceptance of eugenic 'science'. When however we consider the values that scientists held it makes more sense. The belief was that science was not ethically neutral, but that it was on the side of progress for humanity. From there the belief in 'scientifically' engineering the biological progress of humans was not so far, at least rhetorically speaking. ${ }^{19}$

\section{Two examples of idiosyncrasy in the treatment of values in theories of rational belief}

Plainly there is a programme of work here that I cannot possibly undertake, or even advance much, in the space remaining. What I am going to do is illustrate idiosyncrasy over the role of values in rational belief by a couple of examples and then conclude.

The first example is a matter of equivocation on 'values.' When I introduced the distinction between values and evidence I stipulated that I meant ethical values, in the broad sense of ethical, that is, those things constitutive of worthwhile life. Sometimes, however, when speaking of values in this context people speak of epistemic values. But the latter term is ambiguous over the crucial distinction around which I have organised this discussion, the distinction between values and evidence. On the one hand, epistemic values might be about what questions are important, or about the value of knowledge or excellence in believing. As such they are ethical values. On the other hand, they might be epistemic standards constituting truth conducive methodology and the intellectual virtues accompanying it such as open-mindedness, curiosity, intellectual rigour and diligence. All of these I subsumed under evidence. But my distinction between values and evidence is not a distinction between the normative and the non-normative, it is a distinction within normativity. The issue between strict evidentialists and pragmatists is a question over the nature of the normativity had by evidence as such, whether it is intrinsically directive or not. By failing to make this distinction the interference in the role of evidence by values can be rationalised on the grounds that values are ineliminable from enquiry. But of course, the whole issue is not whether epistemic value, that is, what I have subsumed under evidence, is ineliminable but whether ethical value is ineliminable. I agree that

\footnotetext{
${ }^{19}$ This is not to deny other and more obnoxious inputs to the acceptance of eugenics.
} 
value is ineliminable, but this argument to that conclusion is just a cheat, and worse than a cheat, it is a source of idiosyncratic theorising about science.

Notoriously, Kuhn was criticised as an irrationalist on this basis ${ }^{20}$. Although Kuhn denied his work had this import, his work was understood by others in precisely this vein. For example, there are social scientists who aim at using the outputs of their research to advance a political agenda. Some use biased methodologies and reject criticism by denying the existence of an impartial basis from which to criticise their methodology. The reason for the no-impartial-basis claim is the fact that people are not ethically neutral, they have ethical commitments and interests, i.e. ethical values, but clearly that does not entail the impossibility of epistemic impartiality as a constraint on methodology.

The second example is a well known difficulty of empirical enquiry which can be an occasion for the action of values in enquiry. It is impossible to conduct an enquiry with a completely open mind. There are infinitely many hypotheses that might be entertained and for any hypothesis there are infinitely many kinds of data that might be relevant to confirming or rejecting it. How then should we cut them down? Presumably we want some principled way of discerning hypotheses worth considering and relevant kinds of data. Unfortunately, there are infinitely many hypotheses that might be entertained for which principles are correct and infinitely many kinds of data that might be relevant to choosing the principles. So the problem recurs, and recurs at every level. This difficulty appears in many guises, for example Popperians (e.g. Bartley 1964) got into difficulty of circularity or regress in trying to defend critical rationalism (is it itself falsifiable or up for defeat by criticism?) and more recently in the framing problem in artificial intelligence. It has its roots in any attempt to formulate rationality in terms of rules, where presumably one needs rational rules to choose the rules, and so on (e.g. see Brown 1988, Ch. 2) . Fodor offers an engaging description of our difficulties here and concludes that

It strikes me as remarkable...how regularly what gets offered as a solution of the frame problem proves to be just one of its formulations. (Fodor 2008, 121)

If Fodor is right (see his remarks about Kyburg and Laudan, pages 117 and 119) strict evidentialism is floundering with this problem. The philosophical obscurity in epistemic standards resultant from this irresoluble regress leaves room for the appeal to values. Hence we meet with Kirkegaardian claims that rationalism (by which he meant something like strict evidentialism) is on a par with Christian faith because to be a rationalist is also to make a leap of faith. Insofar as I have suggested that some concession to pragmatism is unavoidable I am conceding that there is a normative truth lurking here. Setting aside the question of just what it is, there is at least an empirical truth in play. What steps in and cuts short the regress are convictions, often the very same convictions that set us off on the enquiry in the first place. Depending on exactly how and on what basis convictions step in, this might be defensible by pragmatism. But, of course, there are worries here, a worry about path dependence and a worry about the intrusion of values overstepping whatever role is proper to them.

Taking the latter first, any such overstepping may distort our enquiries somehow or other. In particular, it is plausible that conviction can result in loading the dice to get the number we want, that we set out in a way we present as being neutral but which in fact fixes our destination before the enquiry is even under way. So a recognisable feature of ideological conviction is its power to make the wanted truths the centre around which

\footnotetext{
${ }^{20}$ See, for example, the shifting to and fro between epistemic and ethical values whilst appearing to give them the same or very similar roles in the big shifts in science: Kuhn 1970, 185-6.
} 
everything else will be arranged. Heterodox hypotheses are declared heresy, awkward facts declared taboo. Methodologies that will lead in the desired direction and produce the desired evidence are deployed. Epistemic standards that will warrant the desired answers are articulated and their application to evidence is selectively arranged to afford the desired proofs.

The worry about path dependence is deeper than the worry about the improper intrusion of values, and in a sense subsumes that worry. An improper intrusion of values requires a distinction with their proper role whereas path dependence might result from the propriety or otherwise of intrusion depending on the values started from. To put it more finely, whilst there may be some purely formal constraints on the propriety of roles for values, that might be as far as it goes. Granted that there are a variety of substantive values that constitute the good for persons, and that as a result the good for different persons is itself various, respecting the formal constraints on the basis of different substantive values may result in proper but opposing answers to one and the same nonnormative factual question.

That is not an upshot I find at all congenial. Truth wanters are inclined to think that there cannot be proper but opposing answers to one and the same non-normative factual question. ${ }^{21}$ It is, however, in a loose sense a recognisable feature of our experience. Pursuing disagreements frequently moves on to disagreements about methodology, about how evidence counts and in the end about what matters, which is to say, about values. What at the outset seems to be a straightforward and resolvable dispute about facts ends up in a convoluted and frustratingly irresoluble dispute about values.

\section{Conclusion}

I set out to offer a description of a source of pretension to science. This description has been necessarily very broad in order that I could illustrate the nexus of conviction, value and theories of rationality that constitute the particular source of pretension of interest. I think we are familiar with the existence of this source but have not attended to it much in a philosophical way, tending to see it as only a psychological source of distortion. Yet it has played a role in science as well as in pseudoscience and so to dismiss entirely anything whose origins include it may be to rule out of science things we wish to rule in. Insofar as its manifestation has been philosophically considered it has been through the analysis of idiosyncratic treatments of evidence in pseudoscience, and that is itself very important. Indeed, we should see those analyses as illuminating a wider tendency to subscribe to idiosyncratic theories of rational belief. I have suggested that the role of value in rational belief has been neglected and that as a consequence our understanding of this source has been cruder than it needs to be. In particular, if some variety of pragmatism is true we cannot simply dismiss this source as irrationalism. In so doing we have neglected an entirely distinct range of theory in which idiosyncrasy can manifest.

If we are to advance our understanding of the borders of science and pseudoscience we need better analyses of the proper and improper roles of values and convictions in rational belief. My own convictions are that the truth is paramount and that as a consequence we are required to permit the widest ranging and most open enquiries, however obnoxious we find them. Taboo is forbidden. Heresy must be tolerated. Despite these convictions I do not think that strict evidentialism can be defended. Features that are ethical in the broadest sense, that is to say, features determinative of worthwhile lives, must be among the determinants of right belief. Absent such features, whilst there may be

\footnotetext{
${ }^{21}$ Modulo such complications as possessing different evidence, the possibility of justified belief in a falsehood and so on.
} 
much that is correct or incorrect to believe, and whilst correctness of belief is belief in accordance with evidence, there would be nothing we ought to believe, in the directive sense of 'ought', because it wouldn't matter what we believed. Instead I seek to defend factorism of some kind. I answer the toughest challenges to the requirement to believe the truth on the basis that insofar as beliefs are relevant to settling hard practical and ethical conflicts only the truth is a neutral ground; hence this defence is based in impartiality but allows some retreat from truth when partiality is properly in play. It seems to me that such a theory makes evidentialist practice right for the most part. I would be very disturbed if something beyond factorism were true. The upshot of granting values a role that results in proper path dependence seems to be either that living in illusion can be rational or that reality is relative, it is literally your reality, as your values make it. My conviction is that this cannot be true: it is, however, what some pseudoscientists seem to believe. 


\section{Literature Cited}

Adler, Jonathan Eric 1999. The Ethics of Belief: Off the Wrong Track. Midwest Studies in Philosophy, 23 pp. 267-85.

Adler, Jonathan Eric 2002. Belief's Own Ethics. Cambridge, Mass. ; London: MIT Press. Online at http://www.netLibrary.com/urlapi.asp?action=summary\&v=1\&bookid=74721

Alston, William P. 1988. The Deontological Conception of Epistemic Justification. Philosophical Perspectives, 2 pp. 257-99.

Bacon, Francis 1620/1994. Novum Organum. Peru: Open Court.

Bartley, William Warren 1964. The Retreat to Commitment. London: Chatto \& Windus. Broome, John 2006. Reasons. In Reason and Value: Essays on the Moral Philosophy of Joseph Raz. Eds. Pettit, P. et al pp. 29-55. Oxford: Oxford University Press. Reprinted in - Broome, J. Website at Oxford University.

Brown, H 1988. Rationality. London: Routledge.

Bulbulia, Joseph A 2007. The Evolution of Religion. In Oxford Handbook of Evolutionary Psychology. Eds. Dunbar, R. I. M. and Barrett, L. pp. 621-36. Oxford: Oxford University Press.

Caplan, Bryan Douglas 2007. The Myth of the Rational Voter : Why Democracies Choose Bad Policies. Princeton, N.J.: Princeton University Press.

Conee, Earl Brink \& Feldman, Richard 2004. Evidentialism : Essays in Epistemology. Oxford: Oxford University Press. Online at http://www.loc.gov/catdir/toc/fy046/2004300585.html

Dancy, Jonathan 2000. Practical Reality. Oxford: Oxford University Press.

Dobbs, Betty Jo Teeter 1975. The Foundations of Newton's Alchemy, or, the Hunting of the Greene Lyon. Cambridge: Cambridge University Press.

Engel, Pascal Forthcoming. In Defence of Normativism About the Aim of Belief. In The Aim of Belief. Ed. Chan, T. pp. 65-107. Oxford: Oxford University Press. Online at

http://www.unige.ch/lettres/philo/enseignants/pe/Engel\%202011\%20In\%20Defens e\%20of\%20Normativism\%20about\%20the\%20Aim\%20of\%20Belief.pdf

Feldman, Richard 2000. The Ethics of Belief. Philosophy and Phenomenological Research, 60 (3), pp. 667-95. Online at http://www.jstor.org/stable/2653823

Fodor, Jerry A. 2008. Lot 2: The Language of Thought Revisited. Oxford: Clarendon Press. Online at http://dx.doi.org/10.1093/acprof:oso/9780199548774.001.0001

Gluer, Kathrin \& Wikforss, A 2009. Against Content Normativity. pp 31-70. Online at http://mind.oxfordjournals.org/content/118/469/31.abstract

Haack, Susan 1997. The Ethics of Belief Reconsidered. In The Philosophy of Roderick $M$. Chisholm. Eds. Chisholm, R. M. and Hahn, L. E. pp. xviii, 738 p. Chicago, Ill.: Open Court.

Hechter, Michael 1987. Principles of Group Solidarity. Berkeley ; London: University of California Press.

Heil, John 1983. Believing What One Ought. Journal of Philosophy, 80 pp. 752-64.

IDEA 2011. Faq: Isn't Intelligent Design Just a Movement Trying to Push a Political Agenda? Intelligent Design and Evolution Awareness Centre. Online at http://www.ideacenter.org/contentmgr/showdetails.php/id/1188

Kuhn, Thomas S. 1970. The Structure of Scientific Revolutions. 2nd ed. Chicago ; London: University of Chicago Press. 
Meiland, Jack W 1980. What Ought We to Believe? Or the Ethics of Belief Revisited. American Philosophical Quarterly, XVII (1), pp. 15.24.

Moore, George Edward 1903. Principia Ethica. Cambridge: Cambridge University Press.

Pascal, Blaise 1670. Pensees De M. Pascal Sur La Religion Et Sur Quelques Autres Sujets. A Paris: Chez Guillaume Desprez.

Percival, Philip 2002. Epistemic Consequentialism. Proceedings of the Aristotelian Society, Supplementary Volumes, 76 pp. 121-68. Online at http://www.jstor.org/stable/4106966

Polanyi, Michael 1966. The Tacit Dimension. 1st ed. Garden City, N.Y: Doubleday.

Prichard, Harold Arthur 1912. Does Moral Philosophy Rest on a Mistake? Mind, 21 (81), pp. 21-37. Reprinted in - Ed. Ross, W. D. Moral Obligation. Essays and Lectures by H. A. Prichard. Oxford: Oxford University Press. - to which page references refer.

Quine, Willard van Orman. 1951. Two Dogmas of Empiricism. Philosophical Review, 60 pp. 20-43.

Rabinow, Paul \& Sullivan, William M 1979. The Interpretive Turn: Emergence as an Approach. In Interpretative Social Science: A Reader. Eds. Rabinow, P. and Sullivan, W. M. Berkeley: University of California Press.

Rasmusen, Eric 2007. Games and Information : An Introduction to Game Theory. 4th ed. Malden, MA ; Oxford: Blackwell Pub. Online at http://www.loc.gov/catdir/toc/ecip0620/2006029009.html

Raz, Joseph 1975/1999. Practical Reason and Norms. 2nd ed. Oxford: Oxford University Press.

Rosenberg, Jay 2002. Thinking About Knowing. Oxford: Clarendon Press.

Sampson, E E 1978. Scientific Paradigms and Social Values: Wanted--a Scientific Revolution. Journal of Personality and Social Psychology, 36 pp. 1332-43.

Schafer-Landau, R 2006. Ethics as Philosophy: A Defence of Ethical Non-Naturalism. In Metaethics after Moore. Eds. Horgan, T. and Timmons, M. pp. 209-32. Oxford: Clarendon Press. Online at http://www.loc.gov/catdir/toc/ecip0518/2005023277.html

Schroeder, Mark Andrew 2007. Weighting for a Plausible Humean Theory of Reasons. Nous, 41 (1), pp. 138-60.

Shackel, Nicholas 2004. On the Obligation to Be Rational. Doctoral Thesis, University of Nottingham.

Sidgwick, Henry 1906/1981. The Methods of Ethics. Indianapolis: Hackett.

Sosa, Ernest 2010. Value Matters in Epistemology. Journal of Philosophy, 107 (4), pp. 167-90.

Spence, A Michael 1973. Job Market Signalling. Quarterly Journal of Economics, 87 (3), pp. 355-74. Online at http://dx.doi.org/10.2307\%2F1882010

Stanley, Jason 2005. Knowledge and Practical Interests. Oxford: Oxford University Press. Online at http://www.oxfordscholarship.com/oso/public/content/philosophy/9780199288038 /toc.html

Steglich-Petersen, Asbjørn 2006. No Norm Needed: On the Aim of Belief. The Philosophical Quarterly, 56 (225), pp. 499-516.

Stove, David Charles 1991. What Is Wrong with Our Thoughts? A Neo-Positivist Credo. . In The Plato Cult and Other Philosophical Follies. pp. 179-205. Oxford: Blackwell.

Trivers, Robert 2011. Deceit and Self-Deception : Fooling Yourself the Better to Fool Others. London: Allen Lane.

van Frassen, Bas C 1976. To Save the Phenomena. Journal of Philosophy, 73 (18), pp. 623-32. 
Velleman, James David 2000. On the Aim of Belief. In The Possibility of Practical Reason. pp. 244-81. Oxford: Clarendon Press.

Wedgwood, Ralph 2002. The Aim of Belief. Nous, 16 pp. 267-97.

Williams, Bernard 1985. Ethics and the Limits of Philosophy. London: Fontana. 